\title{
COMPUTER SIMULATION OF MICROSTRUCTURE OF THE FILMS DEPOSITED BY MEANS OF A SPUT'TERING PROCESS
}

(Tokyo Institute of Polytechnics)

\section{Simulation Model : Sputtering system : Facing target sputtering system Film material : Cobalt, Sputtering gas: Argon gas}

(1) Transportation of sputtered particles from target to substrate $\star$ Monte Carlo method (Calculation of the trajectories of each sputtered particles) Incidence angles and energy of sputtered particles arriving at substrate

(2) Deposition of sputtered particles on film surface :

$\star$ Surface migration of deposited particles : Muller's model

$\star$ Effect of kinetic energy of deposition particles : Molecular dynamics simulation

(3) High energy particle bombardment to the film surface : Molecular dynamics simulation: (Potential function: Morse potential, and Zeigler's Universal potential)

\section{Microstructure of Cobalt Films :}

$\star$ Surface migration due to thermally stimulated hopping Deposition conditions: Substrate temperature : $500 \mathrm{~K}$ and $600 \mathrm{~K}$, Argon gas pressure : 2 mTorr and $10 \mathrm{~m}$ Torr, Deposition rate : $100 \AA / \mathrm{min}$
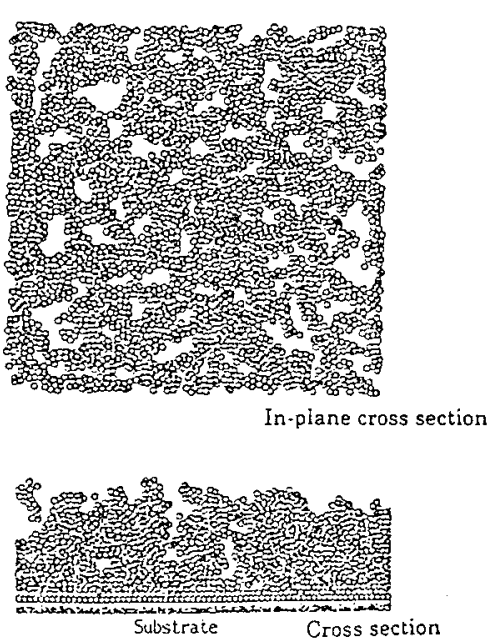

(a) 2 m'Torr, $500 \mathrm{~K}$

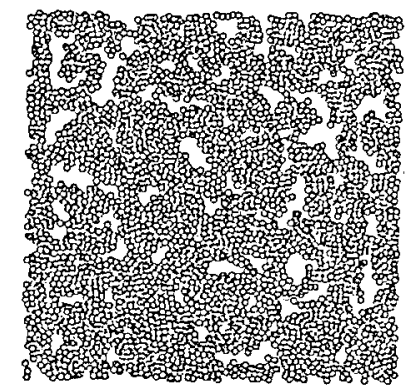

In-plane cross section

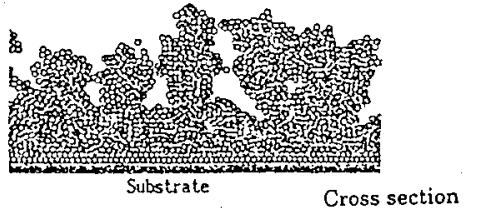

(b) $10 \mathrm{~m}$ Torr, $500 \mathrm{~K}$

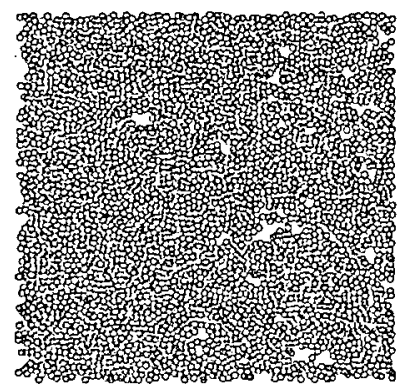

In-plane cross section

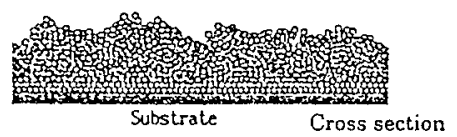

(c) $10 \mathrm{mTorr}, 600 \mathrm{~K}$

$\star$ High energy particle bombardment of the film surface : Movement of atoms in the film induced by the bombardment of high energy argon ions.

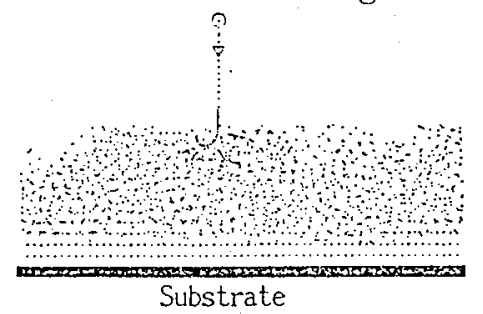

(a) bombardment of $20 \mathrm{eV}$ argon ion

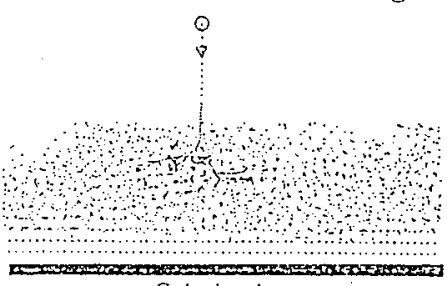

Substrate

(b)bombardment of $100 \mathrm{eV}$ argon ions

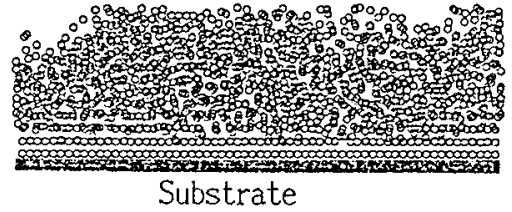

(a) before Ar ion bombardment

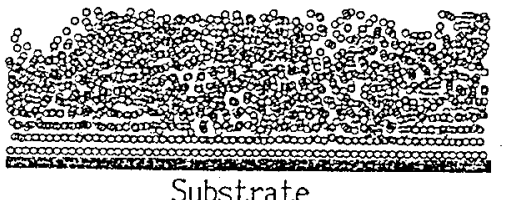

(b) After 10 shots of Ar ions with $20 \mathrm{eV}$ 